\title{
Antimicrobial susceptibilities and random amplified polymorphic DNA-PCR fingerprint characterization of Lactococcus lactis ssp. lactis and Lactococcus garvieae isolated from bovine intramammary infections
}

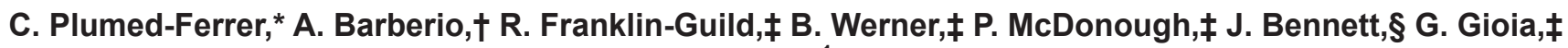 \\ N. Rota,\# F. Welcome, $\ddagger$ D. V. Nydam, $\ddagger$ and P. Moronił\# ${ }^{1}$ \\ ${ }^{*}$ Food Biotechnology, Institute of Public Health and Clinical Nutrition, University of Eastern Finland, PO Box 1627, FI-70210 Kuopio, Finland \\ †Istituto Zooprofilattico Sperimentale delle Venezie, Sez. terr. Vicenza viale Fiume 78, 36100 Vicenza, Italy \\ ¥Cornell University, Animal Health Diagnostic Center, 240 Farrier Road, Ithaca, NY 14853 \\ §Northern Valley Dairy Production Medicine Center, 900 N Wabasha, Plainview, MN 55964 \\ \#Università degli Studi di Milano, Dipartimento di Scienze Veterinarie per la Salute, la Produzione Animale e la Sicurezza Alimentare, \\ Via Celoria 10, 20133 Milan, Italy
}

\begin{abstract}
In total, 181 streptococci-like bacteria isolated from intramammary infections (IMI) were submitted by a veterinary clinic to Quality Milk Production Services (QMPS, Cornell University, Ithaca, NY). The isolates were characterized by sequence analysis, and 46 Lactococcus lactis ssp. lactis and 47 Lactococcus garvieae were tested for susceptibility to 17 antibiotics. No resistant strains were found for $\beta$-lactam antibiotics widely used in clinical practice (penicillin, ampicillin, and amoxicillin), and all minimum inhibitory concentrations (MIC) were far from the resistance breakpoints. Eight strains had MIC intermediate to cefazolin. The random amplification of polymorphic DNA (RAPD)-PCR fingerprint patterns showed a slightly higher heterogeneity for $L c$. lactis ssp. lactis isolates than for Lc. garvieae isolates.

Key words: Lactococcus lactis ssp. lactis, Lactococcus garvieae, intramammary infection, minimum inhibitory concentration, random amplification of polymorphic DNA (RAPD)-PCR fingerprint
\end{abstract}

\section{INTRODUCTION}

Lactococcus lactis is a member of the lactic acid bacteria (LAB), a functional group of gram-positive, microaerophilic cocci that produce lactic acid as the main product of hexose fermentation (Makarova et al., 2006). They also colonize the gastrointestinal and urogenital tracts of humans and animals and are present in foods such as dairy products, fermented meats, fruits, and vegetables. The LAB are intentionally added to several

Received March 16, 2015.

Accepted May 20, 2015.

${ }^{1}$ Corresponding author: pm389@cornell.edu probiotic products because of their potential health benefits (von Wright and Axelsson, 2012).

Lactococcus lactis was thought to be a nonpathogenic bacterium and is used as starter culture for the production of dairy products. In the past, reported opportunistic infections associated with the genus Lactococcus were rare (Collins et al., 1983; Teixeira et al., 1996). Now, Lc. garvieae is classified as an emerging pathogen (Morita et al., 2011), causing infections in fish (Vendrell et al., 2006) and mastitis in the bovine (Collins et al., 1983; Teixeira et al., 1996), and has been associated with human clinical cases (Reimundo et al., 2011). Recently, Lc. lactis has been isolated from diseased fish (Wang et al., 2008; Chen et al., 2012; Pérez et al., 2011), bovine mastitis cases (Wyder et al., 2011; Romero et al., 2011, Plumed-Ferrer et al., 2013, Werner et al., 2014), bird infections (Goyache et al., 2001), and many human clinical infections (Mofredj et al., 2007; Uchida et al., 2011). Isolates from the genus Lactococcus are often misidentified as enterococci or streptococci, and the difficulties in correctly identifying them have probably hindered elucidation of their clinical significance (Goyache et al., 2001). Lactococcus lactis ssp. lactis and Lc. garvieae are now recognized as species with clinical significance for human and veterinary medicine, including bovine IMI associated with mastitis (Werner et al., 2014). Lactococcus lactis has been included in the Qualified Presumption of Safety list of the European Food Safety Authority. It is increasingly found as the cause of human or animal infections, probably due to better identification of infective microorganisms. Under selective pressure, resistance to antibiotics is a common characteristic of bacteria. In the interaction among bacteria, genetic material may be transferred from one bacterium to another, and genes coding for resistance to several antibiotics may be passed on to other bacterial species. Lactococcus may acquire antibiotic resistance 
and survive antimicrobial treatments, and can subsequently act as a reservoir for antibiotic resistance genes for other bacteria (Walther et al., 2008). Because LAB are natural and beneficial inhabitants in many environments (gastrointestinal tract, several foods), strains with antibiotic resistance would not be detrimental to the wellbeing of humans or animals. However, there is some concern that antibiotic resistance in LAB could be transferred to potentially pathogenic bacterial species, complicating the treatment of a disease or infection and leading to the spread of antibiotic-resistant bacteria. Most LAB strains were found to be susceptible to all antibiotics used in past studies. The most frequently found resistance was against tetracycline, followed by resistance to aminoglycosides (Korhonen, 2010). Elliott and Facklam (1996) noted differences in antimicrobial susceptibility between Lc. lactis and Lc. garvieae.

The aim of this study was to examine the MIC of 17 antimicrobials in 46 Lc. lactis ssp. lactis and $47 \mathrm{Lc}$. garvieae isolated from bovine IMI. Moreover, the genotypic characteristics of these bacterial isolates were examined to assess their diversity.

\section{MATERIALS AND METHODS}

\section{Herds}

The isolates examined in this study were from 2 herds (farms A and B) with problems of chronic mastitis, repeat clinical mastitis cases, and individual cows with high SCC due to streptococci-like organisms.

Farm A, a Holstein Friesian herd with 1,693 lactating cows housed in freestalls, had an average daily milk production of $45 \mathrm{~kg} / \mathrm{cow}$ and a bulk tank SCC average of 268,000 cells/mL. From May 1, 2013, through March 31,2014 , the herd exhibited a high prevalence of chronic infections (13\%) as determined by 2 or more consecutive monthly DHIA test-day linear scores $>4.0$ ( $\mathrm{SCC}$ $\geq 200,000$ cells $/ \mathrm{mL}$ ). The prevalence of new infections (new infection risk) was $8.7 \%$. The new infection risk was determined by the number of cows each test day with a current test-day linear score $>4.0$ and a previous test-day linear score $<4.0$. Bedding in all lactating groups was mechanically recycled sand except in the fresh cow pen, where fresh sand was used. Lame cows were housed on a composted pack (wood shavings). Dry cows were housed on recycled sand and pre-fresh heifers were bedded with straw. Feed consisted of a TMR of corn silage, alfalfa haylage, wheat straw, corn grain, various commodities, and protein mix. Cows were milked in a 50-cow rotary parlor.

Farm B, a Holstein Friesian herd with 914 lactating cows housed in freestalls, had an average daily milk production of $39 \mathrm{~kg} / \mathrm{cow}$ and a bulk tank SCC average of 365,000 cells/mL of milk. From May 1, 2013, through March 31, 2014, the herd exhibited a high prevalence of chronic infections $(21.7 \%)$, the new infection risk was $8.8 \%$, as described for farm $\mathrm{A}$, and the prevalence of new infections was $8.8 \%$ of the total lactating cows. Bedding was recycled sand (sand lanes) in all lactating groups, corn stalk pack in the prefresh group, and sand for dry cows. Feed was TMR of corn silage, alfalfa haylage, grass hay, corn grain, various commodities, and protein mix. Cows were milked in a double-20 parallel parlor.

\section{Milk Sampling}

Before sampling, teat ends were carefully cleaned and disinfected with iodine followed by alcohol. The first streams of foremilk were discarded, and then approximately $10 \mathrm{~mL}$ of milk was collected aseptically from each teat into sterile vials. Samples were stored at $4^{\circ} \mathrm{C}$ until bacteriological assays and SCC tests were initiated, immediately after arrival back to the veterinary clinic.

\section{Bacteriological Analysis and Isolates}

The veterinary clinic submitted milk samples from May 2013 through November 2013 to Quality Milk Production Services (QMPS, Cornell University, Ithaca, NY), from which 181 isolates were found and identified as environmental "other" streptococci (meaning not Enterococcus spp., Streptococcus uberis, or Streptococcus dysgalactiae).

Bacteriological cultures were performed according to standards of the National Mastitis Council (NMC, 1999). Ten microliters of each milk sample was spread on blood agar plates (5\% defibrinated sheep blood). Plates were incubated aerobically at $37^{\circ} \mathrm{C}$ and examined after $24 \mathrm{~h}$. Colonies were provisionally identified based on Gram stain, morphology, and hemolysis patterns, and the numbers of each colony type were recorded. Representative colonies were then subcultured on blood agar plates and incubated again at $37^{\circ} \mathrm{C}$ for $24 \mathrm{~h}$ to obtain pure cultures. Gram-positive, catalase-negative cocci were further evaluated using esculin hydrolysis, hemolysis, and Christie, Atkins, Munch-Petersen (CAMP) reaction.

\section{Molecular Identification of Isolates}

Polymerase chain reaction and sequence analysis of $16 \mathrm{~S}$ rDNA and $r p o B$ were used for molecular identification of all isolates. For these analyses, a crude cell DNA lysate was first prepared for each isolate (Furrer et al., 1991). Briefly, pure culture streaks were made 
on tryptic soy agar with $5 \%$ sheep blood plate (Becton Dickinson, Sparks, MD) and incubated for 18 to 24 $\mathrm{h}$ at $37^{\circ} \mathrm{C}$. One isolated colony was transferred to a 1.5-mL tube of Todd Hewitt broth (Becton Dickinson) and incubated for 18 to $24 \mathrm{~h}$ at $37^{\circ} \mathrm{C}$. Then, $250 \mu \mathrm{L}$ of each broth culture was transferred to $1.5-\mathrm{mL}$ microcentrifuge tubes and centrifuged to pellet for $10 \mathrm{~min}$ at $6,000 \times g$. The supernatant was removed and discarded, and the pellet was resuspended in $95 \mu \mathrm{L}$ of $1 \times$ PCR buffer (Roche Applied Science, Indianapolis, IN). A $4-\mu \mathrm{L}$ aliquot of freshly prepared $50 \mathrm{mg} / \mathrm{mL}$ lysozyme (Promega, Madison, WI) solution was added to this suspension and mixed well by pipetting to result in a final concentration of $2 \mathrm{mg} / \mathrm{mL}$ lysozyme. After a 15min incubation at room temperature, $1 \mu \mathrm{L}$ of a $20 \mathrm{mg} /$ $\mathrm{mL}$ proteinase $\mathrm{K}$ (Promega) solution was added to the suspension and mixed, resulting in a final concentration of $200 \mu \mathrm{g} / \mathrm{mL}$ proteinase $\mathrm{K}$. The tubes were incubated up to $2 \mathrm{~h}$ in a heat block set at $58^{\circ} \mathrm{C}$ until the lysates cleared. The enzymes were inactivated for $8 \mathrm{~min}$ at $95^{\circ} \mathrm{C}$. After equilibrating to room temperature, tubes were centrifuged for $3 \mathrm{~s}$ at $6,000 \times g$ to remove condensate from the sides and lids. The crude cell lysates containing the DNA were stored at $-20^{\circ} \mathrm{C}$ and used directly for further analysis. A NanoDrop ND-1000 spectrophotometer (NanoDrop Technologies, Wilmington, DE) was used to determine DNA quantity.

Two PCR were performed to amplify 2 different gene targets: rpoB (Drancourt et al., 2004) and $16 \mathrm{~S}$ rDNA (Greisen et al., 1994). A region of the rpoB gene was amplified using the primer pair rpoBF (5'-AARYTIGGMCCTGAAGAAAT-3') and rpoBR (5'-GCCTTTAACTTCAGACTTATCA-3'). The 16S rDNA gene target was amplified using the primer pair DG74 (5'-AGGAGGTGATCCAACCGCA-3') and P5SH (5'-TGAAGAGTTTGATCMTGGCTCAG-3'). All primers were purchased from Integrated DNA Technologies (IDT, Coralville, IA). The PCR amplification mixtures for both assays were carried out in a total volume of $50 \mu \mathrm{L}$, consisting of $0.25 \mu \mathrm{L}$ of $100 \mu M$ forward and reverse primer, 25.00 $\mu \mathrm{L}$ of GoTaqGreen (Promega), $27.50 \mu \mathrm{L}$ of $\mathrm{H}_{2} \mathrm{O}$, and $2.0 \mu \mathrm{L}$ of cell DNA lysate suspension. All PCR amplifications were performed using the MyCycler Thermal Cycler (Bio-Rad, Hercules, $\mathrm{CA})$. The rpoB gene target was amplified using the following thermal conditions: initial denaturation step of $5 \mathrm{~min}$ at $94^{\circ} \mathrm{C} ; 35$ cycles of $30 \mathrm{~s}$ at $94^{\circ} \mathrm{C}, 30 \mathrm{~s}$ at $50^{\circ} \mathrm{C}$, and 1 min at $72^{\circ} \mathrm{C}$; and a final 7 -min extension at $72^{\circ} \mathrm{C}$. The $16 \mathrm{~S}$ rDNA gene target was amplified using the following thermal conditions: initial denaturation step of $4 \mathrm{~min}$ at $94^{\circ} \mathrm{C} ; 25$ cycles of $1 \mathrm{~min}$ at $94^{\circ} \mathrm{C}, 1 \mathrm{~min}$ at $50^{\circ} \mathrm{C}$, and $1.5 \mathrm{~min}$ at $72^{\circ} \mathrm{C}$; and a final 5 -min extension at $72^{\circ} \mathrm{C}$. The PCR products were analyzed by agarose gel electrophoresis. The expected amplicon size was 740 bp for rpoB and 1,040 bp for $16 \mathrm{~S}$ rDNA.

\section{Clustering}

In preparation for sequencing, excess primers and nucleotides were removed from each sample by treatment with ExoSAP-IT (USB Corporation, Cleveland, $\mathrm{OH})$. Sequencing of each sample was performed in 2 directions using Big Dye Terminator chemistry on an ABI Prism 3700 DNA analyzer (Applied BioSystems, Foster City, CA). Sequences were proofread in SeqMan (version 5.08, Lasergene; DNAStar Inc., Madison, WI), compared with publicly available sequence data using the National Center for Biotechnology Information (NCBI) BLAST programs (Altschul et al., 1997) and identified using interpretive criteria provided by the Clinical and Laboratory Standards Institute (CLSI, 2008).

\section{Randomly Amplified Polymorphic DNA-PCR Analysis}

To further characterize the mastitis isolates, randomly amplified polymorphic DNA (RAPD)-PCR analysis was carried out using 3 primers: P16 (5'-TCGCCAGCCA-3'), P17 (5'-CAGACAAGCC-3'), and P2 (5'-GATCGGACGG-3'). The PCR reaction was performed in a total volume of $25 \mathrm{~mL}$, containing 1 unit of GoTaq DNA polymerase (Promega), 10 pmol of primer, $200 \mathrm{~m} M$ of each dNTP, $3 \mathrm{mM} \mathrm{MgCl}_{2}$, and 50 ng of genomic DNA. Amplifications were performed as follows: initial denaturation at $94^{\circ} \mathrm{C}$ for $5 \mathrm{~min} ; 30$ cycles of $94^{\circ} \mathrm{C}$ for $30 \mathrm{~s}, 24^{\circ} \mathrm{C}$ for $2 \mathrm{~min}$, and $72^{\circ} \mathrm{C}$ for $2 \mathrm{~min}$; final extension at $72^{\circ} \mathrm{C}$ for $5 \mathrm{~min}$. Amplification products were electrophoretically separated in $1 \%$ agarose gels containing SYBR safe DNA gel stain (Life Technologies Ltd., Paisley, UK). Gels were visualized and photographed using the Gel Doc UV transilluminator 2000 (Bio-Rad Laboratories Inc., Hercules, CA). Two replications of each sample and primer were performed to increase the reproducibility of the technique. The DNA fingerprint patterns obtained with the 3 primers were analyzed using GelCompar II (Applied Maths NV, Sint-Martens-Latem, Belgium). Similarity among isolates was determined by means of the Dice comparison and the clustering determined by the unweighted average pair group algorithm.

\section{Antimicrobial Susceptibility Testing}

The MIC of 17 antimicrobials were determined for 46 Lc. lactis ssp. lactis and from 47 Lc. garvieae (1 isolate from farm A did not grow when recultured) isolates 
using the broth dilution test, according to the procedure described in Clinical and Laboratory Standards Institute (CLSI) guidelines VET01-A4 (CLSI, 2013a). A commercially available microdilution MIC system, the Sensititer Compan2F Plate Format veterinary panel and Sensititer ARIS system (Trek Diagnostics Systems, Cleveland, OH), was used. Results were interpreted using CLSI resistance breakpoints according to VET01-S2 guidelines (CLSI, 2013b). When present, specific resistance breakpoints for enterococci or streptococci species were used. For cefpodoxime, the only resistance breakpoint cited was the one for canine wounds. The resistance breakpoint used for ceftiofur was for cattle mastitis organisms. For fluoroquinolones (enrofloxacin and marbofloxacin) and trimethoprimsulfamethoxazole, we used the European Committee on Antimicrobial Susceptibility Testing (EUCAST) clinical resistance breakpoints respectively for ciprofloxacin and trimethoprim-sulfamethoxazole (clinical breakpoints tables, version 4.0; EUCAST, 2014), because of the lack of specific breakpoints for streptococci in the CLSI veterinary guidelines. For clindamycin, the only resistance breakpoints available were those established by the European Food Safety Authority (EFSA, 2012) for the assessment of microorganism used as feed additives. The Sensititer plate reading was performed manually, recording the last concentration of antimicrobial that did not show turbidity or deposit of cells at the bottom of the well.

\section{RESULTS}

On farm A, 130 streptococci were isolated. After DNA sequencing, specific identification included 40 (31\%) Lc. lactis ssp. lactis, 27 (21\%) Lc. garvieae, 5 (4\%) Lc. lactis, 6 (5\%) Lactococcus spp., 37 (28\%) Enterococcus saccharolyticus, 5 (4\%) Streptococcus uberis, $4(3 \%)$ Streptococcus dysgalactiae ssp. dysgalactiae, and $6(5 \%)$ others (Table 1$)$.

On farm B, 51 streptococcal organisms were isolated. After DNA sequencing, specific identification included $6(12 \%)$ Lc. lactis ssp. lactis, 21 (41\%) Lc. garvieae, 1 (2\%) Lc. lactis, 1 (2\%) Lactococcus spp., 18 (35\%) Enterococcus saccharolyticus, 1 (2\%) Streptococcus uberis, $1(2 \%)$ Streptococcus dysgalactiae ssp. dysgalactiae, and $2(4 \%)$ others.

\section{Genotypic Characterization}

Three primers were used to create fingerprint patterns from the total genome of 46 Lc. lactis ssp. lactis and 48 Lc. garvieae isolates collected from farms A and B. Similarity and clustering results were based on 2 rep- licates. The results showed slightly higher heterogeneity for Lc. lactis ssp. lactis isolates than for Lc. garvieae (Figure 1 and Figure 2), even though most of the $L c$. lactis ssp. lactis isolated came from only one farm (farm A). At $75 \%$ similarity, Lc. garvieae isolates separated in one large cluster that included $81 \%$ of the isolates, with $54 \%$ of those being identical at the conditions chosen for the comparison. Lactococcus lactis ssp. lactis isolates, at $75 \%$ similarity, separated in 2 large clusters, the larger one comprising $50 \%$ of the isolates (cluster A) and the slightly smaller cluster including $38 \%$ of the isolates (cluster B). In cluster A, $33 \%$ were identical. For both species, only a few isolates did not cluster together with any other isolate and thus can probably be considered different strains (Figure 3 and Figure 4). Thus, from 48 Lc. garvieae isolates, genotyping analysis showed 4 strains or isolates with low similarity, whereas 6 strains from Lc. lactis ssp. lactis were found from the 46 original isolates. Nine isolates were excluded due to unreproducible fingerprints.

\section{Antimicrobial Susceptibility Testing}

The results of the antimicrobial resistance patterns of Lc. lactis ssp. lactis are given in Table 2. For the $\beta$-lactam antibiotics widely used in clinical practice (penicillin, ampicillin, and amoxicillin), no resistant isolates were found and all MIC were far from the resistance breakpoints. Eight strains had a MIC intermediate to cefazolin, a first-generation cephalosporin. Among the isolates that showed resistance to one or more antimicrobials, 44 were resistant to rifampin, 6 to trimethoprim-sulfamethoxazole, 1 to erythromycin and clindamycin, and 1 to amikacin. The number of isolates displaying multidrug resistance patterns was very low: only 1 isolate was resistant to 3 antibiotics (erythro-

Table 1. Number (\% in parentheses) of mastitis pathogens after DNA sequencing

\begin{tabular}{lcc}
\hline Species & Farm A & Farm B \\
\hline Lactococcus spp. & $6(5)$ & $1(2)$ \\
Lactococcus lactis & $5(4)$ & $1(2)$ \\
Lactococcus lactis ssp. lactis & $40(31)$ & $6(12)$ \\
Lactococcus garvieae & $27(21)$ & $21(41)$ \\
Aerococcus viridans & 2 & 0 \\
Enterococcus aquimarinus & 1 & 0 \\
Enterococcus faecalis & 1 & 1 \\
Enterococcus saccharolyticus & $37(28)$ & $18(35)$ \\
Streptococcus uberis & $5(4)$ & $1(2)$ \\
Streptococcus dysgalactiae ssp. dysgalactiae & $4(3)$ & $1(2)$ \\
Streptococcus suis & 0 & 1 \\
Streptococcus acidominimus & 1 & 0 \\
Pseudochrobactrum spp. & 1 & 0 \\
Total & 130 & 51 \\
\hline
\end{tabular}


RAPD-LL
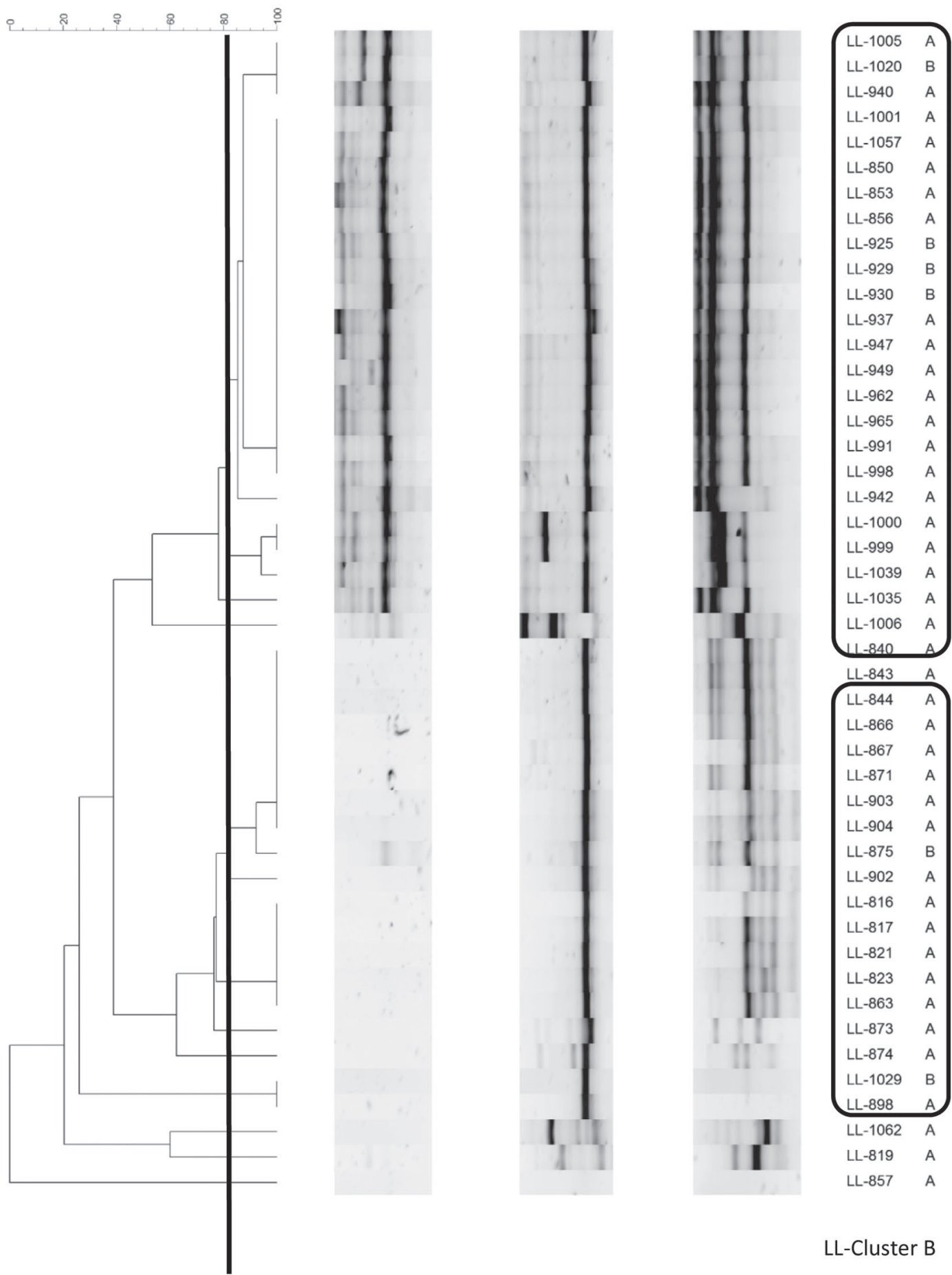

Figure 1. Dendrogram analysis of 46 Lactococcus lactis (LL) ssp. lactis isolates based on their genotypic patterns, which were clustered by the unweighted average pair group algorithm. P2, P16, and P17 indicate different primers used. RAPD = random amplified polymorphic DNA.

mycin, rifampin, and trimethoprim-sulfamethoxazole), 4 isolates were resistant both to rifampin and trimethoprim-sulfamethoxazole, and 1 isolate was resistant to amikacin and trimethoprim-sulfamethoxazole.
The antimicrobial resistance patterns of Lc. garvieae are displayed in Table 3 . The major differences with $L c$. lactis ssp. lactis were the presence of a high number of strains (44) resistant to trimethoprim-sulfamethoxazole 


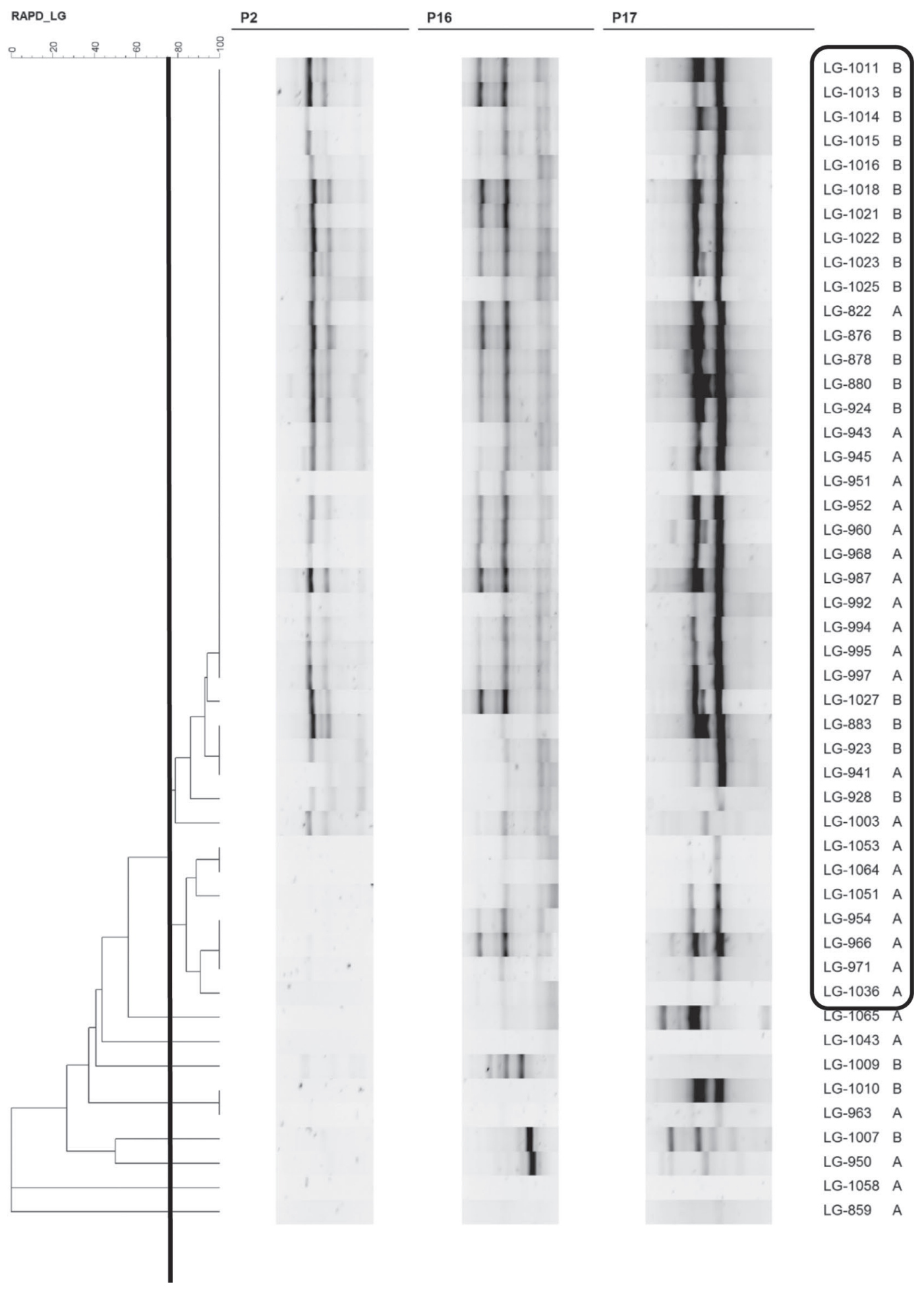

Figure 2. Dendrogram analysis of 48 Lactococcus garvieae (LG) isolates based on their genotypic patterns, which were clustered by the unweighted average pair group algorithm. P2, P16, and P17 indicate different primers used. RAPD = random amplified polymorphic DNA.

and the presence of 2 isolates resistant to cefazolin and 1 to chloramphenicol. Lactococcus garvieae also differed greatly in susceptibility to clindamycin. Most of the $L c$. garvieae isolates (43 out of 47 ) were resistant to this antibiotic and all were susceptible to erythromycin, the other macrolide antibiotic tested. The great majority 

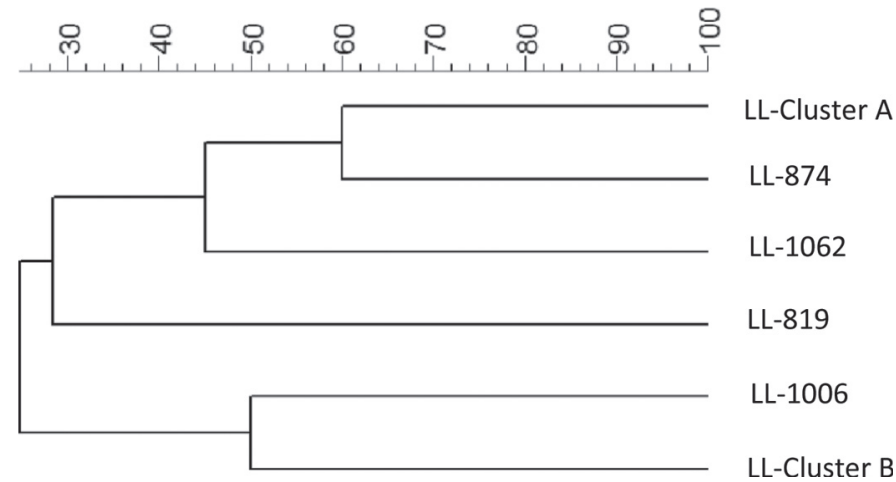

Figure 3. Dendrogram analysis of Lactococcus lactis (LL) strains. The LL clusters contain the following isolates: (A) 1005, 1020, 940, 1001, 1057, 850, 853, 856, 925, 929, 930, 937, 947, 949, 962, 965, 991, $998,942,1000,999,1039,1035 ;$ (B) $840,843,844,866,867,871,903$ $904,875,902,816,817,821,823,863,873$ (some isolates were excluded due to low reproducibility).

of Lc. garvieae isolates were resistant to rifampin as the isolates of Lc. lactis ssp. lactis. Regarding multidrug resistance patterns, 39 strains were resistant to both rifampin and trimethoprim-sulfamethoxazole, 2 isolates were resistant to 3 antimicrobials (rifampin,

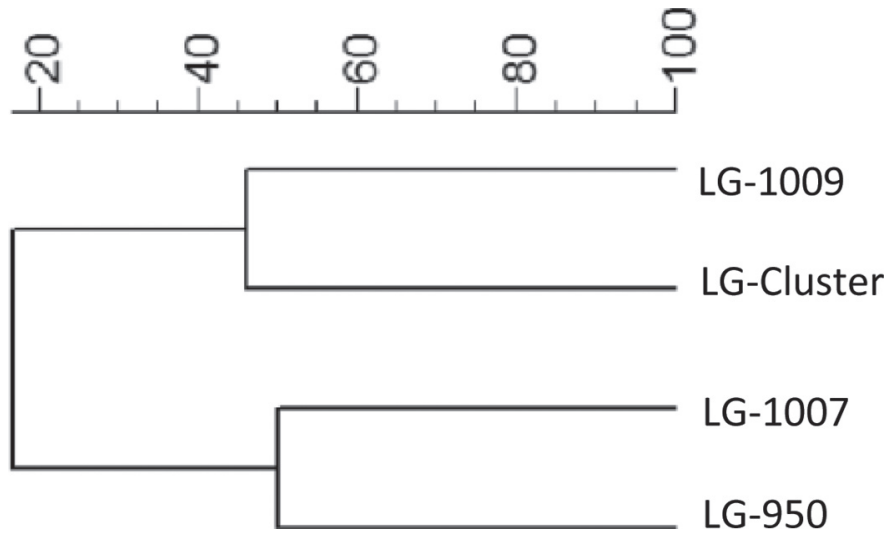

Figure 4. Dendrogram analysis of the Lactococcus garvieae (LG) strains. The LG cluster contains the following isolates: 1011, 1013, $1014,1015,1016,1018,1021,1022,1023,1025,822,876,878,880,924$, 943, 945, 951, 952, 960, 968, 987, 992, 994, 995, 997, 1027, 883, 923, 941, 928, 1003, 1053, 1064, 1051, 954, 966, 971, 1036, 1010, 963 (some isolates were excluded due to low reproducibility).

trimethoprim-sulfamethoxazole, cefazolin), and 2 isolates coupled resistance to rifampin and trimethoprimsulfamethoxazole, respectively, with resistance to chloramphenicol and amikacin.

Table 2. Minimum inhibitory concentrations of the 17 antimicrobial agents tested for 46 Lactococcus lactis ssp. lactis isolates ${ }^{1}$

\begin{tabular}{|c|c|c|c|c|c|c|c|c|c|c|c|c|}
\hline Antimicrobial & Breakpoint $^{2}$ & \multicolumn{11}{|c|}{$\mathrm{MIC}(\mu \mathrm{g} / \mathrm{mL})$} \\
\hline Penicillin & $\mathrm{a}$ & 2 & 1 & 17 & 26 & & & & & & & \\
\hline Ampicillin & $\mathrm{a}$ & & 8 & 38 & & & & & & & & \\
\hline Amoxicillin/clavulanic acid (2:1 ratio) & $\mathrm{b}$ & & 44 & 2 & & & & & & & & \\
\hline Imipenem & $\mathrm{c}$ & & & & & 45 & 1 & & & & & \\
\hline Cefazolin & $\mathrm{c}$ & & & & & 3 & 35 & 8 & & & & \\
\hline Cefpodoxime & $\mathrm{d}$ & & & & & & 46 & & & & & \\
\hline Ceftiofur & e & & & 46 & & & & & & & & \\
\hline Trimethoprim/sulfamethoxazole & $\mathrm{f}$ & & & & 40 & 2 & 2 & 2 & & & & \\
\hline Amikacin & $\mathrm{c}$ & & & & & & & 38 & 5 & 1 & 1 & 1 \\
\hline Enrofloxacin & $\mathrm{f}$ & & & 2 & 34 & 8 & 2 & & & & & \\
\hline Marbofloxacin & $\mathrm{f}$ & & & 1 & 1 & 39 & 4 & 1 & & & & \\
\hline Chloramphenicol & $\mathrm{a}$ & & & & & & & 38 & 8 & & & \\
\hline Rifampin & $\mathrm{a}$ & & & & & 2 & & 44 & & & & \\
\hline
\end{tabular}

${ }^{1}$ Resistance breakpoints are highlighted by dark gray shading; intermediate breakpoints are highlighted by light gray shading; cells without shading indicate that no breakpoints were available in the literature.

${ }^{2}$ Where $\mathrm{a}=$ Clinical and Laboratory Standards Institute (CLSI) resistance breakpoint for enterococci; $\mathrm{b}=$ CLSI resistance breakpoint for other organisms; $\mathrm{c}=$ CLSI resistance breakpoint for all microorganisms; $\mathrm{d}=$ CLSI resistance breakpoint for dog wounds; e $=$ CLSI resistance breakpoint for cattle mastitis; $\mathrm{f}=$ European Committee on Antimicrobial Susceptibility Testing (EUCAST) breakpoints for enterococci; $\mathrm{g}=$ European Food Safety Authority (EFSA) resistance breakpoint (EFSA, 2012). 
Table 3. Minimum inhibitory concentrations of the 17 antimicrobial agents tested for the 47 Lactococcus garvieae isolates ${ }^{1}$

\begin{tabular}{|c|c|c|c|c|c|c|c|c|c|c|c|}
\hline Antimicrobial & Breakpoint ${ }^{2}$ & \multicolumn{10}{|c|}{$\mathrm{MIC}(\mu \mathrm{g} / \mathrm{mL})$} \\
\hline Penicillin & a & 1 & 3 & 20 & 23 & & & & & & \\
\hline Ampicillin & a & 2 & 12 & 31 & 2 & & & & & & \\
\hline Amoxicillin/clavulanic acid (2:1 ratio) & $\mathrm{b}$ & 5 & 12 & 27 & 3 & & & & & & \\
\hline Imipenem & c & & & & 46 & 1 & & & & & \\
\hline Cefazolin & c & & & & 5 & 23 & 17 & 2 & & & \\
\hline Cefpodoxime & $\mathrm{d}$ & & & & & 47 & & & & & \\
\hline Ceftiofur & e & & 47 & & & & & & & & \\
\hline Trimethoprim/sulfamethoxazole & $\mathrm{f}$ & & & 3 & & 12 & 32 & & & & \\
\hline Amikacin & $\mathrm{c}$ & & & & & & 32 & 12 & 2 & & 1 \\
\hline Enrofloxacin & $\mathrm{f}$ & & 3 & 10 & 31 & 3 & & & & & \\
\hline Marbofloxacin & $\mathrm{f}$ & & 1 & 4 & 32 & 10 & & & & & \\
\hline Chloramphenicol & $\mathrm{a}$ & & & & & & 44 & 2 & 1 & & \\
\hline Rifampin & $\mathrm{a}$ & & & & 2 & & 45 & & & & \\
\hline
\end{tabular}

${ }^{1}$ Resistance breakpoints are highlighted by dark gray shading; intermediate breakpoints are highlighted by light gray shading; cells without shading indicate that no breakpoints were available in the literature.

${ }^{2}$ Where $\mathrm{a}=$ Clinical and Laboratory Standards Institute (CLSI) resistance breakpoint for enterococci; $\mathrm{b}=$ CLSI resistance breakpoint for other organisms; $\mathrm{c}=\mathrm{CLSI}$ resistance breakpoint for all microorganisms; $\mathrm{d}=$ CLSI resistance breakpoint for dog wounds; e $=$ CLSI resistance breakpoint for cattle mastitis; $\mathrm{f}=$ European Committee on Antimicrobial Susceptibility Testing (EUCAST) breakpoints for enterococci; $\mathrm{g}=\mathrm{European}$ Food Safety Authority (EFSA) resistance breakpoint (EFSA, 2012).

\section{DISCUSSION}

In recent years, several herds have experienced problems with mastitis cases that did not respond well to treatment and with high bulk tank SCC. Although Lactococcus had previously been isolated, it was unclear whether the number of cases observed indicated an increase in disease incidence and growing emergence as a pathogen or whether newer molecular testing allowed identification of lactococcal infections that would previously have been grouped in a simpler classification system of Streptococcus species. The latter was certainly possible, because lactococci are often misidentified as other streptococci-like bacteria based on traditional culture and biochemical techniques (Barrett, 2013). Molecular testing such as PCR and sequencing-based methods provide unequivocal identification of pure cultures of Lc. lactis ssp. lactis and Lc. garvieae originating from bovine IMI cases (Werner et al., 2014).

Establishing and interpreting the MIC of these pathogens could be helpful when designing effective treatment protocols to control and eliminate infections. The results of the MIC tests performed in this study agree with those of other studies that found both $L c$. lactis ssp. lactis and Lc. garvieae to be susceptible to ß-lactam antibiotics (De Fabrizio et al., 1994; Flórez et al., 2007; Walther et al., 2008). The resistance displayed by almost all the isolates of Lc. garvieae has been described as intrinsic to this species (Walther et al., 2008) and has been proposed as a selective criterion for differentiation between Lc. lactis ssp. lactis and $L c$. garvieae (Elliott and Facklam, 1996). High resistance of Lc. lactis ssp. lactis against rifamycins was recorded in previous studies (Orberg and Sandine, 1985; Mathur and Singh, 2005) and confirmed in our study. Furthermore, our results indicated that Lc. garvieae displayed a high resistance toward rifamycins, with the $96 \%$ of isolates being resistant to rifampin. A greater level of resistance toward trimethoprim plus sulfonamides was found in Lc. garvieae isolates compared with the results of a previous investigation (Walther et al., 2008) performed in Switzerland on 31 isolates from mastitis cases: 27 had a MIC below $0.5 / 9.5 \mu \mathrm{g} / \mathrm{mL}$, whereas 32 isolates in our study had a MIC above $2 / 38 \mu \mathrm{g} / \mathrm{mL}$.

The application of molecular fingerprint methods such as RAPD-PCR allowed us to study genetic differences in isolates and identify isolates at the strainspecific level. The results showed that the isolates 
originated from 6 distinct strains of Lc. lactis and 4 distinct strains of Lc. garvieae. Most of the Lc. lactis were rifampin resistant. Isolate LL-1006, a distinctive strain, was resistant to amikacin and trimethoprimsulfamethoxazole, and strain LL-1062 was resistant to trimethoprim-sulfamethoxazole. On the other hand, most of the Lc. garvieae isolates were resistant to rifampin and trimethoprim-sulfamethoxazole. It is not uncommon to find horizontal gene transfer of a plasmid encoding trimethoprim-sulfamethoxazole resistance (Kateete et al., 2013). However, Devirgiliis et al. (2013) suggested that most lactococcal species display intrinsic resistance to trimethoprim. Whether resistance to this particular antibiotic in these isolates was due to horizontal gene transfer or is intrinsic is unknown and remains to be seen in future investigations.

The goal of this study was to lay a foundation of knowledge to support future investigations in the management and treatment strategies of mastitis caused by Lc. lactis and Lc. garvieae. The fact that these organisms did not display in vitro resistance to antibiotics commonly used to treat dairy cattle IMI implies that they might be susceptible and thus successfully treated on-farm in vivo; however, this remains to be tested. Antimicrobial resistance profiling along with accurate identification of these pathogens will enable targeted and early intervention for reduction of chronic IMI.

\section{ACKNOWLEDGMENTS}

The MIC research in this study was partially financially supported by Boehringer Ingelheim Vetmedica (St. Joseph, MO).

\section{REFERENCES}

Altschul, S. F., T. L. Madden, A. A. Schäffer, J. Zhang, Z. Zhang, W. Miller, and D. J. Lipman. 1997. Gapped BLAST and PSI-BLAST: A new generation of protein database search programs. Nucleic Acids Res. 25:3389-3402.

Barrett, M. 2013. Identification, characterization, and management of an emerging mastitis pathogen, Lactococcus lactis ssp. lactis. Final report SareGrant Project Number ONE11-133. Sustainable Agriculture Research \& Education (SARE), University of Maryland, College Park. http://mysare.sare.org/mySARE/ProjectReport. aspx $? \mathrm{do}=$ viewRept $\& p n=$ ONE11-133\&y $=2013 \& \mathrm{t}=12013 \quad$ Final Report.

Chen, M. H., S. Hung, C. Shyu, C. Lin, P. Liu, C. Chang, W. Shia, C. Cheng, S. Lin, C. Tu, Y. Lin, and W. Wang. 2012. Lactococcus lactis ssp. lactis infection in Bester sturgeon, a cultured hybrid of Huso huso $\times$ Acipenser ruthenus, in Taiwan. Res. Vet. Sci. 93:581-588.

CLSI (Clinical and Laboratory Standards Institute). 2008. Interpretive criteria for identification of bacteria and fungi by DNA target sequencing; approved guideline. CLSI document MM18-A. CLSI, Wayne, PA.

CLSI (Clinical and Laboratory Standards Institute). 2013a. VET01A4: Performance standards for antimicrobial disk and dilution susceptibility tests for bacteria isolated from animals; approved standard. 4th ed. CLSI, Wayne, PA.

CLSI (Clinical and Laboratory Standards Institute). 2013b. VET01S2: Performance standards for antimicrobial disk and dilution susceptibility tests for bacteria isolated from animals; second informational supplement. CLSI, Wayne, PA.

Collins, M. D., J. Farrow, B. Phillips, and O. Kandler. 1983. Streptococcus garvieae sp. nov. and Streptococcus plantarum sp. nov. J. Gen. Microbiol. 129:3427-3431.

De Fabrizio, S. V., J. L. Parada, and R. A. Ledford. 1994. Antibiotic resistance of Lactococcus lactis An approach of genetic determinants locations through a model system. Microbiol. Aliments Nutr. 12:307-315.

Devirgiliis, C., P. Zinno, and G. Perozzi. 2013. Update on antibiotic resistance in foodborne Lactobacillus and Lactococcus species. Front. Microbiol. 4:301.

Drancourt, M., V. Roux, P. E. Fournier, and D. Raoult. 2004. rpoB gene sequence-based identification of aerobic gram-positive cocci of the genera Streptococcus, Enterococcus, Gemella, Abiotrophia, and Granulicatella. J. Clin. Microbiol. 42:497-504.

EFSA. 2012. Panel on Additives and Products or Substances used in Animal Feed (FEEDAP); Guidance on the assessment of bacterial susceptibility to antimicrobials of human and veterinary importance. EFSA J. 10:2740-2750.

Elliott, J. A., and R. R. Facklam. 1996. Antimicrobial susceptibilities of Lactococcus lactis and Lactococcus garvieae and a proposed method to discriminate between them. 1996. J. Clin. Microbiol. 34:1296-1298.

EUCAST (The European Committee on Antimicrobial Susceptibility Testing). 2014. Breakpoint tables for interpretation of MICs and zone diameters. Version 4.0, 2014. https://asmsig.files.wordpress. com/2014/11/breakpoint_table_v_4-01-2014.pdf.

Flórez, A. B., M. Danielsen, J. Korhonen, J. Zycka, A. von Wright, J. Bardowski, and B. Mayo. 2007. Antibiotic survey of Lactococcus lactis strains to six antibiotics by Etest, and establishment of new susceptibility-resistance cut-off values. J. Dairy Res. 74:262-268.

Furrer, B., U. Candrian, C. Hoefelein, and J. Luethy. 1991. Detection and identification of Listeria monocytogenes in cooked sausage products and in milk by in vitro amplification of hemolysin gene fragments. J. Appl. Bacteriol. 70:372-379.

Goyache, J., A. Vela, A. Gibello, M. Blanco, V. Briones, S. Gonzalez, S. Tellez, C. Ballesteros, L. Dominguez, and J. Fernandez-Garayzabal. 2001. Lactococcus lactis ssp. lactis infection in waterfowl: First confirmation in animals. Emerg. Infect. Dis. 7:884-886.

Greisen, K., M. Loeffelholz, A. Purohit, and D. Leong. 1994. PCR primers and probes for the $16 \mathrm{~S}$ rRNA gene of most species of pathogenic bacteria, including bacteria found in cerebrospinal fluid. J. Clin. Microbiol. 32:335-351.

Kateete, D. P., U. Kabugo, H. Baluku, L. Nyakarahuka, S. Kyobe, M. Okee, C. F. Najjuka, and M. L. Joloba. 2013. Prevalence and antimicrobial susceptibility patterns of bacteria from milkmen and cows with clinical mastitis in and around Kampala, Uganda. PLoS ONE 8:e63413.

Korhonen, J. 2010. Antibiotic resistance of lactic acid bacteria. PhD Thesis. Department of Biosciences, University of Eastern Finland, Kuopio.

Makarova, K., A. Slesarev, Y. Wolf, A. Sorokin, B. Mirkin, E. Koonin, A. Pavlov, N. Pavlova, V. Karamychev, N. Polouchine, V. Shakhova, I. Grigoriev, Y. Lou, D. Rohksar, S. Lucas, K. Huang, D. M. Goodstein, T. Hawkins, V. Plengvidhya, D. Welker, J. Hughes, Y. Goh, A. Benson, K. Baldwin, J.-H. Lee, I. Díaz-Muñiz, B. Dosti, V. Smeianov, W. Wechter, R. Barabote, G. Lorca, E. Altermann, R. Barrangou, B. Ganesan, Y. Xie, H. Rawsthorne, D. Tamir, C. Parker, F. Breidt, J. Broadbent, R. Hutkins, D. O'Sullivan, J. Steele, G. Unlu, M. Saier, T. Klaenhammer, P. Richardson, S. Kozyavkin, B. Weimer, and D. Mills. 2006. Comparative genomics of the lactic acid bacteria. Proc. Natl. Acad. Sci. USA 103:15611-15616.

Mathur, S., and R. Singh. 2005. Antibiotic resistance in food lactic acid bacteria-A review. Int. J. Food Microbiol. 105:281-295. 
Mofredj, A., H. Bahloul, and C. Chanut. 2007. Lactococcus lactis: An opportunistic bacterium? Med. Mal. Infect. 37:200-207.

Morita, H., H. Toh, K. Oshima, M. Yoshizaki, M. Kawanishi, K. Nakaya, T. Suzuki, E. Miyauchi, Y. Ishii, S. Tanabe, M. Murakami, and M. Hattori. 2011. Complete genome sequence and comparative analysis of the fish pathogen Lactococcus garvieae. PLoS ONE $6: \mathrm{e} 23184$.

NMC (National Mastitis Council). 1999. Laboratory Handbook on Bovine Mastitis. NMC, Madison, WI.

Orberg, P. K., and W. E. Sandine. 1985. Survey of antimicrobial resistance in lactic streptococci. Appl. Environ. Microbiol. 49:538-542.

Pérez, T., J. Luis Balcazar, A. Peix, A. Valverde, E. Velazquez, I. de Blas, and I. Ruiz-Zarzuela. 2011. Lactococcus lactis ssp. tructae ssp. nov. isolated from the intestinal mucus of brown trout (Salmo trutta) and rainbow trout (Oncorhynchus mykiss). Int. J. Syst. Evol. Microbiol. 61:1894-1898.

Plumed-Ferrer, C., K. Uusikylä, J. Korhonen, and A. von Wright. 2013. Characterization of Lactococcus lactis isolates from bovine mastitis. Vet. Microbiol. 167:592-599.

Reimundo, P., M. Pignatelli, L. David Alcaraz, G. D'Auria, A. Moya, and J. A. Guijarro. 2011. Genome sequence of Lactococcus garvieae UNIUD074, isolated in Italy from a lactococcosis outbreak. J. Bacteriol. 193:3684-3685.

Romero, B., M. Morosini, E. Loza, M. Rodriguez-Banos, E. Navas, R. Canton, and R. del Campo. 2011. Reidentification of Streptococcus bovis isolates causing bacteremia according to the new taxonomy criteria: still an issue? J. Clin. Microbiol. 49:3228-3233.

Teixeira, L. M., V. Merquior, M. Vianni, M. Carvalho, S. Fracalanzza, A. Steigerwalt, D. Brenner, and R. Facklam. 1996. Phenotypic and genotypic characterization of atypical Lactococcus garvieae strains isolated from water buffalos with subclinical mastitis and confir- mation of L. garvieae as a senior subjective synonym of Enterococcus seriolicida. Int. J. Syst. Bacteriol. 46:664-668.

Uchida, Y., H. Morita, S. Adachi, T. Asano, T. Taga, and N. Kondo. 2011. Bacterial meningitis and septicemia of neonate due to Lactococcus lactis. Pediatr. Int. 53:119-120.

Vendrell, D., J. L. Balcázar, I. Ruiz-Zarzuela, I. de Blas, O. Gironés, and J. L. Múzquiz. 2006. Lactococcus garvieae in fish: A review. Comp. Immunol. Microbiol. Infect. Dis. 29:177-198.

von Wright, A., and L. Axelsson. 2012. Lactic acid bacteria: An introduction. Pages 1-16 in Lactic Acid Bacteria: Microbiological and Functional Aspects. 4th ed. S. Lahtinen, A. C. Ouwehand, S. Salminen, and A. von Wright, ed. Taylor \& Francis Group LLC, CRC Press, Boca Raton, FL.

Walther, C., A. Rossano, A. Thomann, and V. Perreten. 2008. Antibiotic resistance in Lactococcus species from bovine milk: Presence of a mutated multidrug transporter $m d t(\mathrm{~A})$ gene in susceptible Lactococcus garvieae strains. Vet. Microbiol. 131:348-357.

Wang, P. C., Y. Lin, L. Liaw, R. Chern, and S. Chen. 2008. Lactococcus lactis subspecies lactis also causes white muscle disease in farmed giant freshwater prawns Macrobrachium rosenbergii. Dis. Aquat. Organ. 79:9-17.

Werner, B., P. Moroni, G. Gioia, L. Lavín-Alconero, A. Yousaf, M. E Charter, B. M. Carter, J. Bennett, D. Nydam, F. L. Welcome, and Y. H. Schukken. 2014. Short communication: Genotypic and phenotypic identification of environmental streptococci and association of Lactococcus lactis ssp. lactis with intramammary infections among different dairy farms. J. Dairy Sci. 97:6964-6969.

Wyder, A. B., R. Boss, J. Naskova, T. Kaufmann, A. Steiner, and H. U. Graber. 2011. Streptococcus spp. and related bacteria: Their identification and their pathogenic potential for chronic mastitisA molecular approach. Res. Vet. Sci. 91:349-357. 